\title{
A FICÇÃo: UMA APOSTA ÉTICO-POLÍTICA PARA AS CIÊNCIAS ${ }^{\star}$ http://dx.doi.org/10.1590/1984-0292/1327
}

Rodrigo Lages Silva $\star \star$

Faculdade Cenecista de Osório, Osorio, RS, Brasil

\section{RESUMO}

Apresento o conceito de ficção como um recurso metodológico para as ciências, partindo da proposta genealógica de Michel Foucault que compreende a ficção como uma potência de desestabilização dos regimes de saber/poder, assim como de interpelação dos regimes de sensibilidade com que o presente é percebido. Nesse sentido, o termo ficção constitui uma alternativa éticopolítica ao conceito de utopia, uma vez que este faz funcionar estratégias macropoliticas e universalizantes, ao passo que a fiç̧ão oferece uma alternativa micropolítica para a problematização da realidade atual para além da configuração histórica com que ela se apresenta.

Palavras-chave: ficção; ciência; método.

\section{FiCTION: AN ETHICAL-POLITICAL ANTE TO SCIENCES}

\begin{abstract}
I present the concept of fiction as a methodological tool for contemporary science, through the Michel Foucault's genealogical approach thatunderstands fiction as potency for destabilizing the knowledge/power regimes, as well as to challenge the sensibility regimes in which one can perceive the present. Hence the term fiction is an ethical-political alternative to the concept of utopia, since utopia enhances macro politics and universalizing strategies, as fiction offers a micro politic alternative to interrogate actual reality beyond the historical form as it presents itself.
\end{abstract}

Keywords: fiction; science; method.

^ Esse artigo é resultado de uma pesquisa financiada pela CAPES.

$\star \star$ Endereço para correspondência: Faculdade Cenecista de Osório. Rua 24 de maio 141 - Centro.

95520-000 - Osorio, RS - Brasil.E-mail: lagesesilva@gmail.com 


\section{INTRODUÇÃo}

Quando Robinson Crusoé, no livro de Michel Tournier (1985), Sexta-feira ou os limbos do pacífico, dá-se conta de que ficará na ilha por muito mais tempo do que tinha suposto inicialmente, ele cria uma das primeiras leis que vão reger o funcionamento da ilha Speranza: todo o pensamento deve ser dito em voz alta.

Sabendo que está privado da companhia de outros homens e de toda informação, dos dissensos e também dos neologismos que são produzidos no uso corriqueiro da linguagem, Robinson luta contra o desgaste, luta contra o tempo, que lhe antagoniza ferozmente. Cada dia na ilha rouba-lhe um pouco do patrimônio de humanidade que naufragou consigo. Repetir os pensamentos em voz alta é conservá-los. A redundância joga contra a entropia. ${ }^{1}$

Esse mesmo princípio tem regido boa parte do que chamamos produção científica ou acadêmica. Também vivemos náufragos em um mundo que nos rouba cada dia um pouco de riqueza. Toda a nossa mitologia busca simbolizar essa perda - de qualidade de vida, de boa convivência com o próximo, de uma relação mais apaziguada com a natureza. Desde a expulsão do Éden até a sucessão das eras metálicas (ouro, bronze e ferro) narradas por Ovídio (1983), percorremos o curso da queda e não fazemos diferente de Robinson ao repetir e repetir, incessantemente, as nossas razões, os nossos pensamentos, os argumentos que buscam justificar serem os nossos modos de viver e de produzir as melhores estratégias para enfrentar a decadência.

É nesse contexto que a interrogação surge como uma importante ferramenta metodológica para a pesquisa.

Questionar é uma maneira de interromper a repetição maníaca das ideias que se pretendem conservar. A pergunta, o problema, produz desvio, faz gaguejar, introduz uma vacilação que permite à linguagem enganar momentaneamente a entropia. Desvia o pensamento de sua repetição paranoica.

Assim, temos que muitas investigações científicas ou acadêmicas começam com uma pergunta suficientemente simples e otimamente forte para produzir esse desvio, esse devir. O grau mínimo de variação inicial para o grau máximo de diferença final.

Mas nem todas as investigações começam por uma pergunta. É que por vezes, o pensamento deixa-se levar pela ilusão. Desdenha das comprovações físicas e lógicas, desconhece a entropia, ou melhor, não a toma em consideração. Deixa o investigador iludido, isto é, em meio ao jogo - in ludus -, no meio da ação e não no começo. Não estar no começo significa não naufragar, ou então, desconhecer que se está nessa condição.

Iludidos, não podemos diferenciar a ilha do continente, não temos pensamento algum a conservar nem a fazer desviar. Falamos em voz alta, diferentemente de Robinson, porque falamos uma língua pela primeira vez e por isso não 
nos cabe perguntar, apenas dizer os nomes das coisas, ou melhor, inventá-las; dizer o nome das coisas, ou melhor, encená-las; dizer o nome das coisas, ou melhor, delirá-las, dizer o nome das coisas, ou melhor, ficcioná-las...

Este artigo pretende, sem negar a potência das investigações críticas e hipotéticas, afirmar as possiblidades de um pensamento que se situa ao lado do delírio, da ilusão, do que já se chamou - com certa razão - de "esquizo" (DELEUZE; GUATTARI, 2010), mas que eu vou insistir em chamar de ficcional, porquanto, meu compromisso não é especificamente o de incomodar um saber psiquiátrico nem um saber psicanalítico, mas o de problematizar as inflexões de um utilitarismo positivista sobre o campo "ético-epistêmico". Isto é, interessa-me flagrar certas flexões contemporâneas entre o modo de produção das coisas e valores, e os modos de viver e de pensar.

Com isso, assim como o "esquizo" nunca se opôs ao saudável, mas ao paranoico. O ficcional a que eu me refiro não se opõe ao real, mas ao constituído, ao produzido. O ficcional é uma potência que habita a produção, mesmo daquilo que é absolutamente palpável e material. E o faz por meio do jogo ou do brinquedo, ou seja, por meio da ação lúdica. "Não conheço outros modos de lidar com grandes tarefas senão o jogo [...]” (NIETZSCHE, 1995, p. 51, grifo do autor).

Estar no jogo é ser um jokerman, aquele que joga o jogo da sua própria vida. Não um playboy, aquele que joga (to play) um jogo de competição, um jogo de vencedores e perdedores, de premiações e aposta de riquezas. O jokerman é o bobo da corte, se não agrada ao rei, este o manda matar. Seu jogo (to joke) é uma brincadeira, uma diversão, mas, sobretudo uma franqueza. Só ele consegue dizer aquilo que o rei não admitiria ouvir fora de um contexto diversionista. Sua verdade só emerge no mesmo momento de sua ilusão e de seu arriscar-se.

Esse artigo pretende ocupar temporariamente o plano que atravessa a psicologia como ciência humana, para pensar um fazer científico que se aproxime da narrativa, das artes, da invenção de linguagens e que, por isso mesmo, pense uma ciência capaz de parrhesía, a franqueza de que nos falava Foucault (2006) a propósito das práticas de si na Grécia antiga. Ficcionar é inventar mundos e os novos mundos não estão destinados apenas a serem ocupados, mas a perturbar àqueles em que vivemos. Mais do que utopias, precisamos de ficções. A ficção como será argumentada nesse texto não é o reino dos escapistas ou dos inocentes. Não se opõe ao inexorável real que se presentifica dissolvendo ilusões (a castração! há castração!). O que a ficção tensiona é o passado enquanto ilusão histórica, para resgatar o passado como condição de contemporaneidade (AGAMBEN, 2009). ${ }^{2}$ A ficção é amiga das forças que habitam o real sempre presente e que de algum modo resistem às formas que lhe dão uma inteligibilidade histórica.

\section{Ciência, POder, história E Genealogia.}

No ensaio introdutório do livro A sociedade contra o Estado, Pierre Clastres (1979) investe contra uma premissa clássica na antropologia: a de que os povos autóctones construíram sociedades em que está ausente o poder político, 
mais do que isso, que são primitivas por não constituírem poder político. O livro de Clastres talvez seja a última convulsão do longo processo de expurgo etnocêntrico que a antropologia cultural realizou ao revisar criticamente suas bases fundacionais. Diz Clastres (1979, p. 15):

[...] o selvagem de qualquer tribo índia ou australiana considera a sua cultura superior a todas as outras sem se preocupar em assegurar sobre elas um discurso científico.

O que quero ressaltar, contudo, é a conclusão principal do autor a respeito do poder dos "selvagens". Para Clastres, o que de fato diferencia os autóctones é terem construído uma sociedade em que o poder raramente se afirma como coerção e em que as condições para que um indivíduo "obedeça" a outro são muito excepcionais, como no caso da guerra, por exemplo. Clastres argumenta que os "civilizados" não encontram o poder nos "selvagens" justamente porque o etnocentrismo só os permite buscar o poder enquanto coerção ou obediência; e conclui: não é o poder político que está ausente entre os selvagens, mas o poder como coerção, como obediência à autoridade. Ao afirmar, porém, essa diferença tão avassaladora para a tese clássica pela qual a antropologia vem diferenciando "primitivos" de "modernos", Clastres $(1979$, p. 22) faz uma última afirmação ao final do ensaio que merece ser debatida: "[...] o poder politico como coerção ou como violência é a marca das sociedades históricas, quer dizer, das sociedades que trazem consigo a causa da inovação, da mudança, da historicidade".

Ao denunciar, portanto, que há uma qualidade não coercitiva do poder entre os ditos primitivos, Clastres vai além e afirma que nesta ausência de coerção o que se abstém não é poder, mas a história, isto é, a formação de regimes de inteligibilidade sobre o passado. Mais do que isso, que a inteligibilidade histórica do passado dá-se sempre coextensivamente a uma noção de novidade, de inovação, de desenvolvimento, de progresso.

Ora, evidentemente o passado não precisa da história para ser pensado. Em diversas outras instituições o passado comparece: nos ritos, nos mitos, nas artes, nos transes místicos em que os mortos falam desde o passado direto para os vivos. O que o antropólogo nos adverte, pois, é que a nossa pretensão de modernidade está intimamente conectada com um modo especial de entender o passado o qual chamamos de história.

Penso que é importante fazer essa alusão porque se trata aqui, justamente, de compreender o tipo especial de relação com o tempo que o fazer científico vem postulando desde a modernidade em sua pretensão de veridicção. A ontologia moderna é histórica no sentido de que compreende a realidade como a consequência, no presente, de condições iniciais passadas (PRIGOGINE; STENGERS, 1997). Não há verdade, do átomo ao cosmos, que na ciência moderna possa existir fora da história, fora de uma linearidade causal regida por leis naturais transcendentes. É a história, então, que garante a universalidade do pensamento moderno e científico, o qual vai poder falar doravante tanto dos astros, como das reações químicas, ou das formações sociais autóctones com o 
mesmo grau de certeza, com a mesma segurança. E quem garante essa certeza é precisamente aquela história a qual, nos advertia Clastres, está intimamente ligada ao tema da força e da coerção. A história como racionalidade científica hegemônica que só conhece o progresso: do animal ao racional; do selvagem ao civilizado; do pobre ao rico; em todas estas "ascensões" a história secreta na ciência um otimismo e um idealismo absolutamente não científicos.

É, pois, menos para entender algo da singularidade dos selvagens que eu faço alusão ao trabalho do antropólogo, do que para problematizar o nosso olhar pretensamente moderno, racional e científico como efeito de certas lutas, certas imposições de saber e de poder que constituem não apenas uma versão da história, mas a própria condição de possibilidade do fazer histórico.

Quando Walter Benjamin (1994a) diz que o historiador está conectado empaticamente com os vencedores, não se trata de que a história seja a versão dos que "detém" um poder. Mas que é porque há vencedores, porque há conflitos, porque há coerções, porque há uma organização (Estados, instituições, modos de produção, modos de vida) que pressupõem o uso da força ou da violência, mais do que isso, que racionalizam e economizam essa violência, é que há história. E se a história é o axioma que universaliza a ciência, tanto mais claro fica que o fazer científico constitui a versão moderna do argumento de autoridade que a religião ou a soberania absolutista constituíram no passado e a propósito do qual a modernidade emergiu para tentar substituir.

A proposta metodológica de Benjamin (1994b) de escovar a história a contrapelo fala, portanto, da instauração sobre a superfície histórica de um campo inventivo em que o novo não comparece como inovação, mas como intempestivo, como diferença, como desvio, nunca como combustível para o motor do progresso.

Em Foucault (1979a) o trabalho genealógico também encontra lugar na inversão da narrativa histórica que, ao invés de partir de um ponto de origem no passado para deslindar o presente, parte de traços, fragmentos, tecnologias do presente para encontrar um passado irredutível à origem, um passado complexo, habitado por forças e por conflitos, mais do que por formas e por consensos.

Quando analisa o tema do Estado contemporâneo, no curso "Em defesa da sociedade", Foucault (2002) inverte uma premissa clássica da sociologia - aquela de Clausewitz para quem "a guerra é a continuação da política por outros meios". Segundo essa concepção, somos naturalmente solidários e racionais, espontaneamente organizados em sociedades de razão para as quais as leis, via de regra, são suficientes para mediar conflitos. Sociedades em que o poder político se opõe ao uso da força. Apenas nas intermitências da razão, nas ambivalências da lei, na incontornabilidade do conflito é que se instaura a guerra - a resolutividade pela força daquilo que a sociedade em seus meios políticos falhou em apaziguar. 
Foucault (2002, p. 22), por sua vez, afirma: "a política é a guerra continuada por outros meios". Para o autor, a razão comparece sempre depois, para tornar justificável a violência, mais do que para evitá-la. A razão, e especialmente a razão de Estado, empresta à violência um sentido e uma utilidade, faz dela imprescindível, até mesmo desejável. Inscreve a violência como condição para a ordem e para a paz.

O estado e a universalidade do Estado é que vão ser, a um só tempo, o móbil e o campo de batalha da luta [...]. Ela vai se desenrolar essencialmente através e em direção da economia, das instituições, da produção, da administração. Vamos ter uma luta civil, em comparação à qual a luta militar, a luta sangrenta, só pode ser um momento excepcional, ou uma crise, ou um episódio (FOUCAULT, 2002, p. 269).

Foucault nos fala, portanto, do paradoxo que nos constitui como indivíduos na modernidade. Somos civilizados, somos modernos, somos racionais na medida em que não precisamos exercer constantemente a violência e a força uns contra os outros. Temos internalizadas as normas e as expectativas da sociedade. Esta sociedade, porém, em seu poder político não é outra coisa que uma continuidade "por outros meios" das relações de força e coerção. Continuidade por meios decerto mais sutis e flexíveis, mas que podem conviver perfeitamente com a forma explícita e dura da violência, desde que ela seja empregada contra alvos específicos - certos segmentos da população, certas classes desviantes ou perigosas, certas raças - e na dose necessária para a manutenção da ordem e a paz.

Esse deslocamento do poder, então, que não será doravante um efeito de imposição de um sujeito sobre outro, mas que se constituirá na relação entre um conjunto de ações sobre outro conjunto de ações (FOUCAULT, 1995), um poder que incide menos sobre os sujeitos em si do que sobre suas virtualidades, suas ações possíveis, incitando ações desejáveis, coibindo as indesejáveis. Um poder que prefere a obediência consentida e, mais ainda, o consentimento não persuadido, oferecido espontaneamente como modo natural ou normal de agir. Esse regime de poder convive tranquilamente com a guerra e com o uso da força a qual ele vai direcionar para a manutenção do equilíbrio social, do direito da impessoalidade das leis, eis o paradoxo.

Falar em ficção como um conceito que pode interpelar a ciência, não significa um apelo ao belo ou ao sensível, em oposição ao mundo duro e violento. Se a ciência pode incluir uma dimensão narrativa, autoral, não é com a condição de abrir mão de seus efeitos de poder, mas porque é assumindo o poder como inerente à prática histórico-científica, pode vir a pensar o seu exercício com rigor ético.

Auctor era o nome que o Império Romano concedia ao general que ganhava um novo território para a urbe, e autor é quem faz aumentar (augere) um território mediante a adição de outros. Criar um território imagináriocimenta uma forma de autoridade, portanto (COPÓN, 2000, p. 129-130, grifo do autor). 
Não se trata aqui de retomar o "bom selvagem". Se os autóctones não construíram um poder político fundado na coerção e por isso não fizeram história, não é porque fossem naturalmente tendentes à paz e à solidariedade e não à guerra e ao conflito, mas que seus atos de criação, autoria ou conquista prescindiam de uma estrutura centralizada que sequestrasse o território da arte, da religião, do artesanato, enfim, da produção, para fins de conservação e expansão de um poder estatal que, fechado tautologicamente sobre si mesmo, agisse simultaneamente como modo de operação e princípio finalístico.

O Estado é, nesse sentido, o efeito e o produtor da história. É ele quem se apropria do passado e o inscreve numa linearidade evolutiva para a qual o "estado de direito" constitui, ao mesmo tempo, o ponto de convergência de todas as lutas, todas as emancipações e o entreato de uma relação tão livre com a natureza e com os semelhantes como a do "bom selvagem" do qual seríamos descendentes. O Estado como princípio de inteligibilidade arrecada as forças produtivas e as ordena segundo suas injunções conservadoras e universalizantes. Por isso que ao definir o seu objetivo com o projeto genealógico, Foucault (1979b, p. 170) afirmou que queria ir ao encontro dos "saberes sem senso comum e que foram deixados de lado", ir ao encontro deles para "torná-los capazes de oposição e de luta" (FOUCAULT, 1979b, p.172), produzir "uma insurreição dos saberes contra a instituição e os efeitos de poder e de saber do discurso científico" (FOUCAULT, 1979b, p. 174).

Na genealogia, são as virtualidades que a história não cessa de esconjurar que são buscadas. E, por isso, é que sua realização tem efeitos de ficção no presente. Como Foucault afirmou num um texto menor. ${ }^{3}$ Tão secundário na sua bibliografia que o editor da coleção "Ditos e Escritos" brasileira não achou por bem incluí-lo na sua versão.

[...] nunca escrevi nada além de ficções. Com isso, não quero dizer que estejam fora da verdade. Parece-me possível fazer a ficção trabalhar na verdade, induzir efeitos de verdade com um discurso ficcional e, de algum modo, fazer com o que o discurso de verdade suscite, fabrique alguma coisa que ainda não existe, portanto "ficcione". "Ficciona-se" a história a partir de uma realidade política que a torna verdadeira, "ficciona-se" uma política que ainda não existe a partir de uma verdade histórica (FOUCAULT, 1994, p. 236 apud RODRIGUES, 2009, p.233). ${ }^{4}$

\section{FICÇão E UTOPIA}

Os gregos tinham muitas palavras para falar sobre o funcionamento da narrativa. Dentre eles, destaco dois: a poiesis e a diegesis. A poiesis refere-se, numa narrativa, à qualidade daquilo que é novo, que é desviante, que é da ordem da criação, da produção. Já a diegesis era o termo grego usado para referir ao que nas tragédias gregas dava à história uma vivacidade, uma consistência; aquilo que produzia uma sensação espaço-temporal. É diferente da verossimilhança, pois uma história pode ser totalmente inverossímil e ainda assim parecer real para o 
expectador ou leitor. Poiesis e diegesis formam, num certo sentido, um par antitético, posto que a poiesis pura nunca duraria o suficiente para formar diegesis, seria a variação contínua, a criação que não se conserva, que flui incessantemente. A diegesis, por sua vez, para efetivar-se precisa esquivar-se da poiesis, esconjurar a poiesis para encontrar a paz necessária a sua inteligibilidade-mundo.

A utopia, por sua vez, enquanto gênero literário, tal como o romance, a poesia, a escrita científica, a biográfica, etc., é um modo de narrar, de dar coesão e coerência a elementos heterogêneos, de produzir uma experiência espacial, portanto, e tem de lidar com estes princípios da arte narrativa. A utopia, contudo, é um gênero que luta constantemente contra a poiesis. Tudo o que os romances utópicos pretendem é construir um espaço de tal forma ideal que não seja necessário transformá-lo, reconstruí-lo ou reformá-lo.

A utopia é uma ficção que se pretende como modelo global para as cidades, como ideal a ser perseguido. A cidade sem as suas fraquezas, sem aquilo que a faz ruir, que a degenera. É a cidade em perfeito equilíbrio. Mas o perfeito equilíbrio é, na verdade, uma estase. Todo equilíbrio é imperfeito, todo o equilíbrio é "equilibrações"; da mesma forma que o espaço enquanto efeito da união entre diferentes é sempre limitado no tempo, é circunstancial, que circunstanciais são as relações. Por isso, espaço-tempo.

Assim, o que vemos na ficção utópica é a proposta de uma correspondência entre o global ou universal: a cidade ideal, descendente do Olimpo, cidade-modelo de perfeita ordenação espacial e imune aos desgastes do tempo, cidade que se eterniza e que só existe na literatura, só existe como ficção; e o local: as cidades imperfeitas, de geografia acidentada, entregues ao desgaste do tempo, enfim, as cidades em decadência nas quais vivemos e que são descendentes de Tróia - fadadas à ruína, não importa o quão revitalizadas ou pujantes.

Poucas imagens ilustram tão bem a impossibilidade de correspondência entre o local e o global como a utopia. Não é possível fazer corresponder universalmente a experiência do espaço perfeito que temos quando lemos um livro utópico às nossas experiências locais.

[...] nenhuma loucura é a própria loucura, nenhuma ciência é a Ciência, nenhuma pintura é toda a pintura, nenhuma guerra é a guerra absoluta. [...] a expressão jamais se ajusta perfeitamente ao expressado: há distorção (VEYNE, 1983, p. 31).

É essa qualidade do poder de subsumir o local pelo global, isto é, de investir uma aura global em uma experiência local, "a invasão do particular no universal" (SERRES, 2003, p. 151) que o faz tão íntimo da utopia. O poder não cria, como sabemos a partir de Foucault (1995), apenas repressões, mas também faz funcionar realidades. O que me interessa, portanto, é demarcar em que condições a ficção comparece em sua forma utópica, refreando os fluxos, cristalizando os limiares, individualizando e organizando o vivido. E em que condições a ficção é capaz de amplificar um tempo denso "saturado de agoras" (BENJAMIN, 1994b). 
A ficção que me interessa é, pois, aquela que vai embaralhar o mapa das utopias disciplinares, de controle, preventivas. Que vai dar profundidade a ele, ao mesmo tempo em que o distorce; que produz um espaço-tempo repleto de possíveis. A ficção que não segrega diegesis de poiesis.

A síntese da diegesis com a poiesis compatibiliza no paradigma ético-estético a crítica em relação às abordagens idealistas ou transcendentes da natureza $\mathrm{e}$ a potência de criação ou invenção do mundo. A poética não é menos essencial às ficções do que a diegética para produzir as realidades possíveis. Na qualidade de "atraversamento", a poética realiza a inserção de um trans no seio da experiência, no meio das nossas realidades diegéticas; estratégia antiuniversal, portanto. "O transversal barra localmente o universal" (SERRES, 2003, p. 225).

Precisamos das ficções não utópicas, precisamos de narrativas, precisamos da capacidade de estranhar o mundo tal como ele se apresenta em sua naturalidade, pois o problema das utopias não é que elas sejam impossíveis, mas que elas estejam por toda a parte.

\section{CiÊNCIA, MÉTOdo E MOdERNIDADE}

A modernidade científica iniciada no século XVIII junto com o Iluminismo concebeu o mundo como enigma, como conjunto de leis e funcionamentos a serem decifrados. Pensava uma ordenação do mundo que prescindia ao homem ou, ao menos, tomava-o como conjunto de funções, tecidos e órgãos os quais deveriam estar regidos pelas mesmas leis físicas que regem a todos os objetos.

A "mente" ou a "consciência" que formulava as perguntas, entretanto, não lhe eram pertinentes e seguiam pertencendo ao mundo obscuro das conjecturas filosóficas ou teológicas associadas ao longo período de "trevas" da Idade Média; assim como e as atividades concernentes à consciência, a moral e a arte, por exemplo. De um lado haveria as coisas dadas pela natureza, variáveis independentes da existência e do interesse humanos, e do outro lado as coisas inventadas pelo homem, como o conceito de bom e mal, beleza e fealdade etc..

O mundo moderno é completamente natural, todas as coisas têm origem na natureza, inclusive as leis que a regem. Através do conceito de natureza a modernidade pretendeu superar o problema da criação substituindo um Deus transcendente pela transcendência das leis naturais. Elas organizariam e regeriam a vida que, por sua vez, nada pode fazer senão corresponder às suas exigências.

O método experimental era o grande operador dessa epistemologia científica moderna no sentido de garantir que esses dois universos, o humano e o natural, não se misturassem ou, mais precisamente, para que as leis ou os comportamentos inventados pelos homens não contagiassem as leis da natureza.

A utilização de protocolos experimentais estandardizados - aqueles que podem ser repetidos por pesquisadores diferentes e conduzir a resultados semelhantes - passou a distinguir os chamados hard scientists, ou os cientistas das 
áreas exatas e tecnológicas, dos seus colegas das ciências humanas. Ao passo que os últimos buscaram apontar o que há de arbitrário e cultural no mundo, os primeiros dedicaram-se ao que é lógico e natural, isto é, às evidências.

Nessa disputa que é, em grande parte, uma disputa de sentidos que coloca em jogo cosmovisões diferentes, os hard scientists frequentemente lançam mão da seguinte anedota para reforçar suas convicções: "se você se atirar de um prédio, você vai cair e isso não é uma questão de ponto de vista, ou de poder, ou de história, isso simplesmente é o que acontece quando alguém se atira de um prédio".

O que é visado no exemplo acima - e, sem dúvida, alcançado - é a explicitação da irrefutabilidade do "dado". O que os hard scientists normalmente não estão interessados em debater, contudo, é que na sua forma simplificada e racional, o método experimental raramente nos leva além do "dado", ou seja, ele comprova aquilo que a lógica já supõe existir, mas não nos informa sobre o que está por vir, sobre as tensões ou as possiblidades que habitam o presente e o papel que nos toca diante dele.

Nesse sentido, a superação da dicotomia entre as propriedades racionais do mundo natural e os acontecimentos arbitrários do mundo humano precisa ser jogada no terreno da ontologia, isto é, na interpretação não apenas de como o "dado" ganha existência, mas também sobre as potências de transformação ou devir que habitam o "dado". Trata-se de trabalhar num paradigma que não supõe que o futuro já está completamente decidido pelo passado e apostar no presente como potência de desvio, de engendramento, de diferença.

$\mathrm{O}$ fato de que a epistemologia científica moderna se estandardizou e supervalorizou o método experimental não significa que as possibilidades de tal método estejam resumidas ao escopo das intenções cientificistas.

O experimento nem sempre está aí para confirmar o discurso científico. Pode-se dizer que a finalidade de confirmação é sempre secundária à experimentação científica e que, ao arriscar-se para além das fronteiras de um universo já decodificado pela linguagem da ciência hegemônica, não faz outra coisa senão transgredi-la. O momento da confirmação é posterior a um afrontamento inicial. Não há experimentação que possa ser respeitosa com um status quo.

Mas por que afrontar o status quo? Por que ir além do dado? Por que, afinal, é necessário olhar as forças do porvir que habitam o presente?

É que da modernidade para o contemporâneo, passamos de um universo confuso, cuja ordenação oferecida pelas explicações religiosas demonstravase demasiado obscura, demasiado infantilizante, um universo, enfim, que demandava esclarecimentos, que precisava ser explicado, para outra perspectiva de um mundo precário, cuja natureza mais do que ameaçadora surge como um plano complexo ao qual estamos vinculados, um mundo no qual precisamos estar atentos às surpresas que ele nos apresenta, que nos demanda problematizarmos constantemente as relações que estabelecemos com ele. 
De modo que são questões eminentemente éticas e estéticas que assediam o conhecimento: qual a maneira correta de intervir na natureza? Que aparência ou que ordem deve ter o meio-ambiente para sustentar o contingente humano que o habita? Como o homem deve relacionar-se com seu entorno para não esgotá-lo? No final das contas, vivemos um momento em que o paradigma epistemológico da modernidade precisa ser superado. Ou então, colocando o problema nos termos de Latour, Schwartz e Charvolin (1998), os cientistas precisam dar-se conta de que nunca foram modernos e que em realidade não somos e nem nunca fomos capazes de ter uma noção transcendente da natureza, nem para dela extrair qualquer conhecimento irrefutável, nem para ser capaz de antecipar seus destinos, sequer para prever a próxima epidemia bacteriológica, tanto menos para antecipar as mudanças climáticas. Estamos inseridos num universo que se move à revelia de todo o conhecimento e de toda a organização que a modernidade foi capaz de produzir. A atual crise do meio-ambiente, ou melhor, dos meios ambientes, já que se trata de uma pluralidade que não forma um todo, é, segundo esses autores, um exemplo de que nosso modo de relacionar-se com a natureza não é mais moderno do que o de qualquer tribo considerada primitiva pelos antropólogos.

Um coletivo que deve se ocupar do ar, do mar, da água, dos animais selvagens e domésticos, dos micróbios e das estrelas, não é mais pós-moderno do que moderno. Ele é simplesmente não moderno, mergulhado na comum humanidade, antropológico como todos os outros. (LATOUR; SCHWARTZ; CHARVOLIN, 1998, p. 104)

Em suma, a maioridade prometida pelo Iluminismo não passou de uma experiência existencial, foi mais uma atitude do que um êxito cognitivo. $O$ giro epistemológico que nos cabe para "encaixar o meio-ambiente nas ciências humanas" (LATOUR; SCHWARTZ; CHARVOLIN, 1998, p. 124) é a assunção de uma ciência completamente cultural, que não tenha a pretensão de definir os limites do que é natural, mas que aceite seu estado de imanência, que saiba extrair do método experimental, dessa atitude moderna, aquilo que ele tem de possibilidade de criação e de produção. Com isso, o que se pretende é incluir o homem na operação do conhecimento, mas para forçar os limites daquilo que consideramos humano. É preciso superar o natural e o humano num só golpe.

Readequar, portanto, os objetivos das ciências humanas num mundo em que estamos despejados do conforto e da segurança da modernidade científica para um período de incertezas e precariedades significa manter o longo aprendizado dos anos pós-Iluminismo, ou seja, a capacidade de lançarmos um olhar crítico para o nosso tempo, de problematizarmos as estruturas de poder que nos circundam e os mecanismos de subjetivação que nos habitam, sem fazer, contudo, um apelo a um ideal perdido ou a uma redenção futura.

Essa crítica imanente, como disse anteriormente, deve ser realizada no terreno da ontologia. E o que isso significa? Que doravante comentar o estado atual das coisas não está separado da ação de produzir novos sentidos possíveis para elas, sentidos antes impensáveis, de tal maneira que é preciso tornar-se outro para 
pensá-los. Conhecer deixa de ser uma questão de mera percepção do que está dado para aproximar-se da narrativa, essa arte que flerta com a história ao mesmo tempo em que flerta com a mentira. Contar a história do mundo em transformação significa tomar parte na sua usinagem. Isso quer dizer que ao cientista não lhe cabe apenas conhecer o mundo, mas transformá-lo, ou inventá-lo, num processo que não o deixará incólume5. Fazer ciência torna-se fazer a síntese do experimento com a experiência. Um processo no qual a criação do artifício passa a ser também a criação de si. "O sortilégio dessas lutas é que quem as olha também tem que lutá-las!” (NIETZSCHE, 1995, p. 96)

\section{Conclusão}

O fazer científico ao aproximar-se da ficção, seja na sua textualidade, ou na montagem de experimentos que busquem afetar os regimes de sensibilidade, desorientando-os em direção a outros possíveis, precisa sustentar-se sobre um conjunto de sentidos, sobre um campo semântico, mas também dar-lhe sustentação de modo que ele permaneça polissêmico, de modo que ele convoque, que ele atraia, outros sentidos, outros corpos, outros sujeitos; de modo, portanto, que esse sentidos tenham duração e contágio, dois mecanismos que não caminham separados.

Trata-se de uma estratégia que tem afinidade com o caráter artesanal de que Benjamin (1994a) falou a propósito da arte narrativa. Nela trata-se de lidar com o que já está à disposição, de conectar materiais distintos, de buscar uma convergência em conceitos que até então não possuíam uma relação direta. Prática, portanto, de montagem que parece deixar sempre uma fragilidade, uma precariedade ao conceito. Fica sempre uma digital, uma marca da mão do escultor no gesso da obra. Ela nunca é totalmente lisa, totalmente pura.

Entendo que o narrador de Benjamin (1994a) tem algo do bricoleur de Lévi-Strauss (2008), aquele que utiliza meios heteróclitos ou caminhos divergentes para atingir um fim e que "sem jamais completar seu projeto, sempre coloca nele alguma coisa de si" (LÉVI-STRAUSS, 2008, p. 37). Dessa forma, se é verdade que o bricoleur se utiliza de sua estratégia fragmentária para atingir um fim, também é verdade que a ênfase de sua ação é sempre o processo, o ato presente de conectar os diferentes conforme as suas afinidades estéticas e fazer, com isso, que uma potência de obra esteja constantemente sendo colocada em jogo, simultaneamente instaurada e desafiada a cada colagem. É, portanto, para sabotar a luminosidade sedutora dos objetivos finais que uma bricolagem se dá. Esta é sua aposta: ficcionar é desvirtuar o real em sua pureza privatizada

Ficcionar é recordar o caráter excedente desmedido, do inútil, do extravagante, do estético. A ficção efetiva-se como estratégia anticapitalista para as ciências, na medida em que incita encontros, associações, consórcios para a construção de espaços-tempo, de práticas experimentais, de ocupações nas quais o sentido da utilidade ou do pragmatismo não se coloque acima da experiência sensorial, estética ou artística. 
A ficção realiza um tipo de relação alusiva e desviante com o real. Perturba nossas utopias em construção e, assim, fala em nome de "outro mundo possível". Um mundo que não é utópico no sentido de um mundo ideal, mas artificial, inventado com o único objetivo de interrogar as formações de um presente que na sua objetividade moderna é cada vez mais carcerário.

\section{Notas}

${ }^{1}$ Princípio que se aplica tanto à teoria da comunicação quanto à física. No primeiro caso, o da comunicação, a entropia significa que toda a passagem de um meio a outro - da voz para a fita, da luz para o filme, do original para a fotocópia, etc. - ou de um emissor para um receptor, implica perda de informação. A cópia nunca é exatamente tal qual o original. $\mathrm{O}$ disco nunca reproduz toda a extensão da onda acústica. A foto nunca poderá captar toda a emissão de fótons que a cena produz. No segundo caso, o da física, a entropia é o princípio que postula estar o universo em esfriamento progressivo. A expansão do universo implica que os átomos estejam-se separando continuamente, até o ponto em que nada tenha a possibilidade de existir; em que tudo será apenas fria homogeneidade inerte (em física essas três dimensões - calor, movimento e forma - são imbricadas). A entropia é também a função que explica a impossibilidade de um moto-contínuo. Toda a conversão da energia em movimento gera perda de calor.

2 "A contemporaneidade é, portanto, uma singular relação com o próprio tempo, que adere a este e, ao mesmo tempo, dele toma distâncias; mais precisamente, essa é a relação com o tempo que a este adere através de uma dissociação e um anacronismo" (AGAMBEN, 2009, p.59).

${ }^{3}$ Faço jus ao seu método em citá-lo.

${ }^{4}$ Trata-se da entrevista concedida a Lucette Fina, intitulada Les rapports de pouvoir passent a l'interieur des corps, da qual trago o excerto traduzido por Heliana Conde Rodrigues.

${ }^{5}$ É preciso evitar a armadilha da separação entre ação $\mathrm{x}$ interpretação no/do mundo. Uma ação que supõe superar o idealismo porque estaria engajada nas coisas práticas, nas lutas objetivas; e uma interpretação que supõe uma distância dos acontecimentos como pré-condição para um conhecimento puro e universalmente válido. A narrativa como prática científica, coloca o sujeito em meio ao processo, de modo que o seu devir é ao mesmo tempo ação e interpretação no mundo, ele produz um ato de linguagem que não está descolado dos eventos do qual toma parte. 


\section{REFERÊNCIAS}

AGAMBEN, G. O que é o contemporâneo? E outros ensaios. Chapecó: Argos, 2009.

BENJAMIN, W. O narrador: considerações sobre Nicolai Leskov. In:

Magia e técnica, arte e política. São Paulo: Braziliense, 1994a. Coleção Obras Escolhidas, p. 197-221.

BENJAMIN, W. Sobre o conceito da História. In: . Magia e técnica, arte e política. São Paulo: Braziliense, 1994b. Obras Escolhidas, p. 222-234.

CLASTRES, P. A sociedade contra o Estado. Porto: Afrontamento, 1979.

COPÓN, G. Qcquinquagésimoquinta utopía. In: ZUSH. La campanada. Madrid: Museo Nacional Centro de Arte Reina Sofia, 2000. p. 107-133.

DELEUZE, G.; GUATTARI, F. O anti-édipo: capitalismo e esquizofrenia. São Paulo: Ed. 34, 2010.

FOUCAULT, M. Nietzsche, a genealogia e a história. In: MACHADO, R. (Org.). Microfísica do poder. Rio de Janeiro: Graal, 1979a. p. 15-38.

FOUCAULT, M. Genealogia e poder. In: MACHADO, R. (Org.). Microfisica do poder. Rio de Janeiro: Graal, 1979b. p. 167-178.

FOUCAULT, M. O sujeito e o poder. In: RABINOW, P.; DREYFUS, H. Michel Foucault: uma trajetória filosófica. Rio de Janeiro: Forense-Universitária, 1995. p. 231-249.

FOUCAULT, M. Em defesa da sociedade. São Paulo: Martins Fontes, 2002.

FOUCAULT, M. A Hermenêutica do Sujeito. São Paulo: Martins Fontes, 2006.

LATOUR, B.; SCHWARTZ, C.; CHARVOLIN, F. Crises dos meios ambientes: desafios às ciências humanas. In: ARAUJO, H. R. (Org.). Tecnociências e cultura: ensaios sobre o tempo presente. São Paulo: Estação Liberdade, 1998. p. 91-125.

LÉVI-STRAUSS, C. O pensamento selvagem. Campinas: Papirus, 2008.

NIETZSCHE, F. Hecce Homo: com alguém se torna o que é. São Paulo: Cia das Letras, 1995.

OVÍDIO. As metamorfoses. Rio de Janeiro: Tecnoprint, 1983. 
PRIGOGINE, I.; STENGERS, I. A nova aliança. Brasília: UNB, 1997.

RODRIGUES, H. B. C. Entre a 'marca da pantera' e a pantera cor-de-rosa' - Michel Foucault e o processo de desinstitucionalização psiquiátrica. In: MOURÃO, J. C. (Org.). Clínica e Política. Rio de Janeiro: Abaquar/GTNM, 2009. v. 2, p. 231-252.

SERRES, M. O nascimento da física no texto de Lucrécio. São Paulo: UNESP, 2003.

TOURNIER, M. Sexta-feira ou os limbos do pacifico. São Paulo: DIFEL, 1985.

VEYNE, P. O inventário das diferenças: história e sociologia. São Paulo: Braziliense, 1983.

Recebido em: 02 de julho de 2014 Aceito em: 03 de setembro de 2014 